\title{
Bud Development, Return Bloom, and External Bud Appearance Differ among Cranberry Cultivars
}

\author{
Lisa Wasko DeVetter ${ }^{1,4}$, Rebecca Harbut ${ }^{2}$, and Jed Colquhoun ${ }^{3}$ \\ Department of Horticulture, University of Wisconsin-Madison, 1575 Linden Drive, Madison, \\ WI 53706
}

\begin{abstract}
AdDitIONAL INDEX wORDs. biennial bearing, cultivar effects, floral initiation, resource allocation, Vaccinium macrocarpon
Abstract. Recent cultivar releases of cranberry (Vaccinium macrocarpon) have been reported to differ in terminal bud development, biennial bearing tendencies, and external bud appearance. However, verification of these claims and cultivar comparisons with respect to these characteristics are lacking. The objectives of this project were to 1) evaluate flower initiation, bud development, and potential return bloom across several cultivars of cranberry, including recent introductions; and 2) determine the relationship between external appearance of buds and the presence/absence of flower initials. Samples of upright shoots representing the cultivars Searles, Stevens, HyRed, and Crimson Queen were collected from a commercial cranberry marsh located in central Wisconsin during the 2011 and 2012 growing seasons. Collected uprights were separated based on reproductive status (i.e., reproductive or vegetative). Buds were then dissected and analyzed for presence/absence of flower initials using light and scanning electron microscopy. Growing degree days (GDD) were calculated and related to the progression of bud development. Flower initials were first observed on 29 July 2011 and 10 July 2012, or 290 and 322 GDD, respectively. Excluding 'Searles', dates of initiation were the same across all cultivars and did not differ based on reproductive status. Descriptive bud data demonstrated that wider buds are more likely to contain flower initials and overall bud width tended to be greater among recent cultivar releases. Biennial bearing tendencies were also lower among recently released cultivars, as exhibited by greater occurrences of potential return bloom. Results from the study provide evidence that recently released cultivars differ in bud development, have an increased potential for return bloom, and overall wider buds. These findings suggest newer cultivars may have different mechanisms regulating mixed bud development and other yield-contributing factors.
\end{abstract}

Cranberry is a perennial vine native to northeastern continental America (Eck, 1990). Vertical stems, known as uprights, develop terminal buds that may be mixed or vegetative. Mixed buds contain flower initials that overwinter and produce fruit the next year, whereas vegetative buds lack flower initials and only contain a vegetative meristem. Alternating patterns of mixed bud formation on individual uprights leads to biennial bearing and it has been shown that fruiting uprights are less likely to develop mixed buds (Eaton, 1978; Elle, 1996; Roper et al., 1993). Competition for carbohydrates during simultaneous fruit and bud development has been provided as an explanation for biennial bearing tendencies in cranberry (Baumann and Eaton, 1986; Strik et al., 1991). However, recently released cultivars are reputed to exhibit extensive return bloom (Roper, 2006). Return bloom occurs when a fruiting upright develops a mixed bud, thereby circumventing biennial bearing.

Much of the previous research on cranberry buds is based on cultivars that are becoming less common within the industry (Goff, 1901; Lacroix, 1926; Lenhardt and Eaton, 1977; Roberts and Struckmeyer, 1943). Plantings of recently released cultivars

Received for publication 13 May 2013. Accepted for publication 1 Aug. 2013. We acknowledge the following for their valued contributions to this project: Chris and Lisa Rezin at Rezin Berries, Wisconsin State Cranberry Growers Association (WSCGA), Wisconsin Cranberry Board, Inc., and the Biological and Biomaterials Preparation, Imaging, and Characterization Laboratory (BBPIC) at the University of Wisconsin-Madison. We also thank Emily Beaver for technical assistance.

${ }^{1}$ Graduate Research Assistant. Research presented is part of a doctoral thesis. ${ }^{2}$ Assistant Professor.

${ }^{3}$ Professor.

${ }^{4}$ Corresponding author. E-mail: 1wasko@wisc.edu. have been increasing amidst reports that these cultivars exhibit favorable production characteristics, such as extensive return bloom. However, evaluations and comparisons of these recent introductions relative to traditional ones are lacking. Furthermore, the relationship between external bud appearance and the presence/absence of flower initials has not been systematically evaluated, particularly among recent cultivar releases (Lenhardt and Eaton, 1977; Patten and Wang, 1994). External bud appearance is an important characteristic because of its extensive use as a metric for yield prediction. This approach to prediction is qualitative and entails visual assessment of buds during the year before anticipated harvest. Large and round buds are assumed to be mixed and have the potential to contribute to the next year's crop. Small and narrow buds, on the other hand, are assumed to be vegetative. Despite the prevalence of this approach, the margin of error between predicted and actual yield can exceed $15 \%$ (T. Dittl, personal communication). Such a large margin of error renders the reliability of this metric questionable for the cranberry industry. This metric may become increasingly problematic if external bud appearance varies dramatically, which necessitates an evaluation across cultivars.

This project sought to address the lack of information on bud initiation and development across different cultivars of cranberry, including recent introductions. Specific objectives of this project were to 1) evaluate flower initiation, bud development, and potential return bloom across cultivars; and 2) determine the relationship between external appearance of buds and the presence/absence of flower initials. Information on these characteristics will be valuable as investigators and industries explore how to optimize production and management of the different cultivars available to growers. 


\section{Materials and Methods}

Material Collection. Samples were collected from a commercial cranberry marsh in Wood County, WI (lat. $44^{\circ} 21^{\prime} 42^{\prime \prime} \mathrm{N}$, long. 89 $\left.57^{\prime} 53^{\prime \prime} \mathrm{W}\right)$. Cultivars collected and information regarding their respective dates of release, parentage, and geographical origin are presented in Table 1. All beds from which samples were collected from were located within a $1.6-\mathrm{km}$ radius of each other and the site was representative of commercial production in Wisconsin. Approximately 100 uprights of each cultivar were randomly collected from one bed per cultivar every 2 weeks from 5 Mar. to 7 Dec. 2011. Sample size was reduced to 70 uprights per collection date in 2012, which was done to expedite bud analysis while maintaining statistical robustness. Based on 2011 data, upright collection in 2012 targeted the period of floral initiation and bud development ( 5 July through 30 Aug.). Sampling was increased to two times per week during this interval. Sampling also occurred 14 Sept. and 26 Oct. 2012, which enabled harvest and post-harvest assessment of buds. 'Searles' uprights were not collected on 26 Oct. 2012 as a result of bed renovation decisions made by the grower.

Plant growth and yield data were collected from three randomly placed rings per bed. Each ring measured $491 \mathrm{~cm}^{2}$ and these data were collected from the same beds where upright collection occurred. Data collected include upright density (total number of uprights per unit area), percentage floral induction (percentage of reproductive uprights per unit area), fruit yield (total berry mass per unit area), berry number (total berry number per unit area), and mean berry weight (total berry mass divided by total berry number per unit area). Temperature data were collected every $30 \mathrm{~min}$ with an environmental data logger (Watchdog 2465 Plant Growth Station; Spectrum Technologies, Plainfield, IL). Growing degree days were calculated using a modified version the cranberry-specific method introduced by DeMoranville et al. (1996). Summation of GDD began 1 Mar. of both years and used base and maximum temperatures of 16 and $30{ }^{\circ} \mathrm{C}$, respectively.

SAMPle PREParation. All material was stored at $4{ }^{\circ} \mathrm{C}$ until bud dissection and analysis. Uprights with flowers or fruit at the time of collection were classified as reproductive, whereas nonflowering/fruiting uprights were considered vegetative. When flowers and fruit were absent, the presence of persistent pedicels was used to determine reproductive status. Bud scales were removed and presence/absence of flower initials within the terminal bud was determined on all collected material with the aid of a dissecting microscope. Descriptive data of buds were collected to test the hypothesis that terminal bud appearance is related to the presence/absence of flower initials. Data collected included bud height, width, and bud size ratio (width/height). These data were recorded from 90 buds per cultivar and year, which were collected on 7 Dec. 2011 and 26 Oct. 2012. Only 2011 descriptive bud data from 'Searles' were analyzed because

Table 1. Cranberry cultivars included in the study, their respective dates of release, parentage, and geographical origin.

\begin{tabular}{lcll}
\hline Cultivar & Release date & \multicolumn{1}{c}{ Parentage } & \multicolumn{1}{c}{ Origin } \\
\hline Searles & 1893 & Native selection & Wisconsin \\
Stevens & 1950 & McFarlin $\times$ Potter & New Jersey \\
HyRed & 2003 & Stevens $\times$ Ben Lear & Wisconsin \\
Crimson Queen & 2006 & Stevens $\times$ Ben Lear & New Jersey \\
\hline
\end{tabular}

the bed was renovated by the 2012 collection period. Dates of collection were chosen to evaluate the post-harvest status of buds, as well as their condition before the beds were protected with winter ice.

IMAGING. Scanning electron microscopy (SEM) was used to determine the date of flower initiation, which occurred when developing buds were too small to see with a dissecting microscope. Thirty representative uprights were prepared as described previously and placed in a fixative solution of $4 \%$ glutaraldehyde $(\mathrm{v} / \mathrm{v})$. Samples were then stored overnight in a vacuum at $4{ }^{\circ} \mathrm{C}$. Samples were subsequently rinsed four times with a $0.05 \mathrm{M}$ $\mathrm{KPO}_{4}$ (pH 7.0) solution before undergoing dehydration with a dilution series of ethanol. The dilution series started at $10 \%$ ethanol (v/v). The concentration was increased by $10 \%$ every 20 min until samples were in a solution of $100 \%$ ethanol (v/v). Final preparation of samples entailed critical-point drying (Samdri 780; Tousimis, Rockville, MD) and sputter coating with a 60/40 gold-palladium-alloy mixture (Auto Conductavac IV; SeeVac, Pittsburgh, PA). Viewing and imaging was performed at $10 \mathrm{kV}$ with a SEM (S-570 $\mathrm{LaB}_{6}$; Hitachi, Tokyo, Japan).

STATISTICAL ANALYSIS. Statistical analyses were performed using the General Linear Model (SAS Version 9.2; SAS Institute, Cary, NC). Tests of significance were done at $\alpha=0.05$ using a least-squares mean (lsmeans) option with a Tukey-Kramer adjustment for multiple comparisons. Means were combined when analyses revealed no significant interaction as a result of year.

\section{Results and Discussion}

Evaluation of Floral initiation. Excluding 'Searles', flower initials were first observed across all cultivars on 29 July 2011 and 10 July 2012, or 290 and 322 GDD, respectively. Figure 1A-B demonstrates this observation for 'HyRed'. Flower initials were observed in the buds of both reproductive and vegetative uprights of 'Stevens', 'HyRed', and 'Crimson Queen'. Presence of flower initials was noted at the same date regardless of reproductive status. These data suggest the potential for extensive return bloom in cranberry, which is discussed in the subsequent section.

Observed initiation dates were similar to those reported by Roberts and Struckmeyer (1943), who identified initials by 29 July in 'McFarlin' buds collected from a marsh located in Wisconsin. Lenhardt and Eaton (1977) also noted the appearance of flower initials by late July in 'McFarlin' buds collected in British Columbia. Defoliation experiments with 'Bergman' grown in British Columbia led to the inference that initiation occurs by 4 July, whereas 'McFarlin' showed no response to defoliation (Eaton, 1978). Earlier reports estimate initiation to occur later in the season. Lacroix (1926) noted flower initials by mid-August in buds of 'Howes' and 'Early Black' grown in Massachusetts. An even earlier study by Goff (1901) reported the appearance of flower initials in an unidentified cultivar from Wisconsin by 16 Sept. Such discrepancies in reported dates of flower initiation may be the result of the technological limitations of imaging techniques used in previous studies, which relied on light microscopy. Use of SEM in this study enabled the early detection of initiation. Such early detection of initiation would have been difficult to observe using traditional light microscopy.

Climatic and/or cultivar effects have been offered as an explanation for some of the differences in observed initiation 

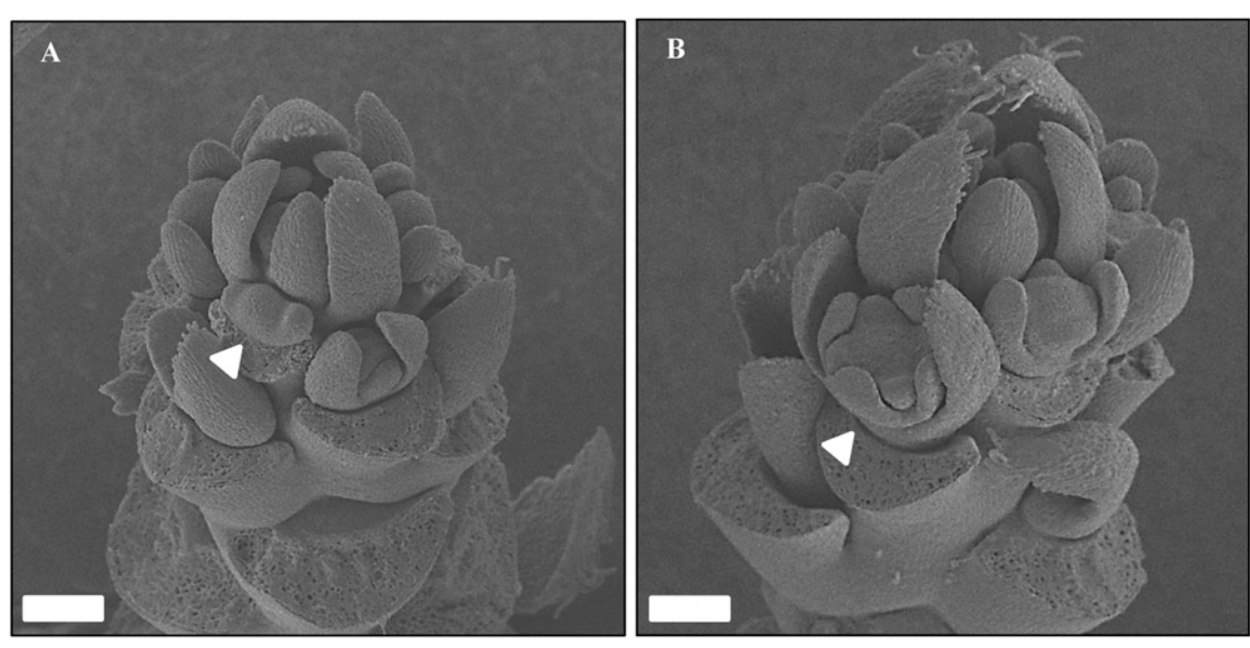

Fig. 1. Scanning electron micrographs of cranberry terminal buds collected in Wisconsin on 29 July $2011(\times 100)$. Flower initials were observed both years in buds collected from (A) vegetative and (B) reproductive uprights. Images presented are of 'HyRed', with similar images obtained from buds of 'Stevens' and 'Crimson Queen'. Arrows denote flower initials (bar $=100 \mu \mathrm{m}$ ).

Table 2. Growing degree days (GDD) calculated from a commercial cranberry marsh located in Wisconsin. ${ }^{\mathrm{z}}$

\begin{tabular}{lcc}
\hline Month & 2011 GDD & 2012 GDD \\
\hline March & 0 & 22 \\
April & 1 & 3 \\
May & 23 & 48 \\
June & 81 & 159 \\
July & 199 & 254 \\
August & 124 & 153 \\
September & 30 & 52 \\
Total & 458 & 691 \\
\hline
\end{tabular}

${ }^{\mathrm{z}} \mathrm{GDD}$ were calculated using a base and maximum temperature of 16 and $30{ }^{\circ} \mathrm{C}$, respectively. Values represent monthly totals for the 2011 and 2012 growing seasons.

dates. However, similar dates of initiation were reported in studies examining 'McFarlin' buds collected in British Columbia and Wisconsin despite the geographical and climatic differences between these two locations (Lenhardt and Eaton, 1977; Roberts and Struckmeyer, 1943). Results from our study further suggest that temperature, as measured by GDD, is not likely the single determinant affecting timing of flower initiation. This is demonstrated by the lack of a correlation between initiation and a specific value of accumulated GDD across the 2 years (290 and 322 GDD in 2011 and 2012, respectively). These results can be corroborated by previous research that has shown certain physiological aspects of cranberry growth and development, such as ethylene and anthocyanin production, are not strongly related to thermal heat accumulation (Hawker and Stang, 1985). The similar timing of floral initiation across the surveyed cultivars in our study is suggestive of a photoperiodic response. Worth noting, however, is that the 2012 growing season was much warmer than 2011. As a result, GDD accumulated more rapidly and flower initials were observed $19 \mathrm{~d}$ earlier compared with 2011 (Table 2). This suggests that there may be an as yet undefined relationship between photoperiod and temperature that affects cranberry floral initiation. Moreover, our study does not strongly support the influence of cultivar on timing of initiation because initials were first observed at the same time across all cultivars, excluding 'Searles'. Previous work with 'Bergman' and 'McFarlin' has also shown initiation dates to be similar among these distinct cultivars (Eaton, 1978; Lenhardt and Eaton, 1977; Roberts and Struckmeyer, 1943). Despite our findings, cultivar effects on initiation cannot be completely discounted because 'HyRed' and 'Crimson Queen' are offspring of 'Stevens' (Table 1). This shared genetic background may influence the observed timing of initiation.

High mortality of terminal buds was observed in 'Searles' during both years. Similar observations were made in a preliminary study that included samples of 'Searles' from three other cranberry-growing sites (data not presented). As such, timing of floral initiation was unable to be accurately determined for this cultivar. Evidence of tipworm (Dasineura oxycoccana), a known causal agent of bud damage, was lacking and suggests death may be the result of other physiological or environmental mechanisms.

Cultivar Comparisons. Yield was greatest across both years for the two recently released cultivars, HyRed and Crimson Queen, whereas yields of 'Stevens' and 'HyRed' were similar (Table 3). 'Searles' yielded the least fruit, which was consistent with growers' experience. Upright density and berry number were the same across all cultivars, whereas floral induction and mean berry weight had significant cultivar-by-year effects $(P<0.0001$ and $P=0.005$ for floral induction and mean berry weight, respectively). In 2011, floral induction was greatest among 'Stevens', 'HyRed', and 'Crimson Queen'. No differences in floral induction were observed in 2012. Analyzed by year, 'Crimson Queen' consistently produced larger berries, whereas 'Searles' produced the smallest. Mean berry weight of 'Stevens' was the same as 'HyRed' in 2011 and 'Crimson Queen' in 2012.

Greater mean berry weight may account for the increase in total yield produced by the new cultivars of HyRed and Crimson Queen, regardless of berry number being the same across all cultivars and floral induction only differing in 2011. Review of nitrogen application rates suggests that fertility is not the primary cause of our observed differences. 'Searles' received the least nitrogen relative to the other cultivars $\left(28.6\right.$ and $30.2 \mathrm{~kg} \cdot \mathrm{ha}^{-1}$ in 2011 and 2012, respectively). 'Stevens' received 45.5 and $39.2 \mathrm{~kg} \cdot \mathrm{ha}^{-1}$ in 2011 and 2012, respectively, whereas 'HyRed' received $61 \mathrm{~kg} \cdot \mathrm{ha}^{-1}$ in 2011 and $54.8 \mathrm{~kg} \cdot \mathrm{ha}^{-1}$ in 2012. 'Crimson Queen' also received greater rates of nitrogen with $57.1 \mathrm{~kg} \cdot \mathrm{ha}^{-1}$ in 2011 and $65 \mathrm{~kg} \cdot \mathrm{ha}^{-1}$ in 2012. These nitrogen fertility rates suggest that the reduced yield of 'Searles' is not the result of surplus nitrogen contributing to excessive vegetative growth at the expense of fruit development. Inherent variation within the beds may have masked some of the significant differences presented in Table 3. Nevertheless, our results are consistent with grower experience in Wisconsin.

Four categories of uprights were identified during the collection of descriptive bud data. Those categories include: 1) vegetative uprights with flower initials in the bud;2) vegetative 
Table 3. Upright density, percentage floral induction, yield, berry number, and mean berry weight of four cranberry cultivars collected in Wisconsin during 2011 and 2012.

\begin{tabular}{|c|c|c|c|c|c|c|c|}
\hline \multirow[b]{2}{*}{ Cultivar } & \multirow[b]{2}{*}{ Upright density (no. uprights) } & \multicolumn{2}{|c|}{ Floral induction $(\%)^{\mathrm{z}}$} & \multirow[b]{2}{*}{ Fruit yield (g) } & \multirow[b]{2}{*}{ Berry no. } & \multicolumn{2}{|c|}{ Mean berry wt (g) } \\
\hline & & 2011 & 2012 & & & 2011 & 2012 \\
\hline Searles & $210.5 \mathrm{a}^{\mathrm{y}}$ & $23.4 \mathrm{~b}$ & $11.3 \mathrm{a}$ & $85.0 \mathrm{c}$ & $76.7 \mathrm{a}$ & $1.13 \mathrm{~b}$ & $1.19 \mathrm{c}$ \\
\hline Stevens & $195.5 \mathrm{a}$ & $77.0 \mathrm{a}$ & $25.2 \mathrm{a}$ & $120.2 \mathrm{bc}$ & $82.7 \mathrm{a}$ & $1.26 \mathrm{ab}$ & $1.74 \mathrm{a}$ \\
\hline HyRed & $166.5 \mathrm{a}$ & $73.3 \mathrm{a}$ & $28.9 \mathrm{a}$ & $166.6 \mathrm{ab}$ & $120.7 \mathrm{a}$ & $1.36 \mathrm{ab}$ & $1.43 \mathrm{~b}$ \\
\hline Crimson Queen & $188.0 \mathrm{a}$ & $72.3 \mathrm{a}$ & $25.3 \mathrm{a}$ & $193.8 \mathrm{a}$ & $76.6 \mathrm{a}$ & $1.52 \mathrm{a}$ & $1.80 \mathrm{a}$ \\
\hline \multicolumn{8}{|l|}{ Significance $^{\mathrm{x}}$} \\
\hline $\mathrm{C}$ & 0.269 & \multicolumn{2}{|c|}{0.089} & 0.003 & 0.057 & \multicolumn{2}{|c|}{$<0.0001$} \\
\hline $\mathrm{Y}$ & 0.069 & \multicolumn{2}{|c|}{$<0.0001$} & 0.013 & 0.006 & \multicolumn{2}{|c|}{$<0.0001$} \\
\hline $\mathrm{C} \times \mathrm{Y}$ & 0.164 & \multicolumn{2}{|c|}{$<0.0001$} & 0.606 & 0.924 & \multicolumn{2}{|c|}{0.005} \\
\hline
\end{tabular}

${ }^{\mathrm{z}}$ Percentage of reproductive uprights per unit area.

y Values are means determined from three $491-\mathrm{cm}^{2}$ sample rings per cultivar bed; means with the same letter within a column are not different at $P \leq 0.05$ using a Tukey-Kramer adjustment.

${ }^{\mathrm{x}}$ Significance $(P$ value $)$ of cultivar $(\mathrm{C})$, year $(\mathrm{Y})$, and $\mathrm{C} \times \mathrm{Y}$ interactions; data were combined across years within a cultivar when there was no significant $\mathrm{C} \times \mathrm{Y}$ interaction.
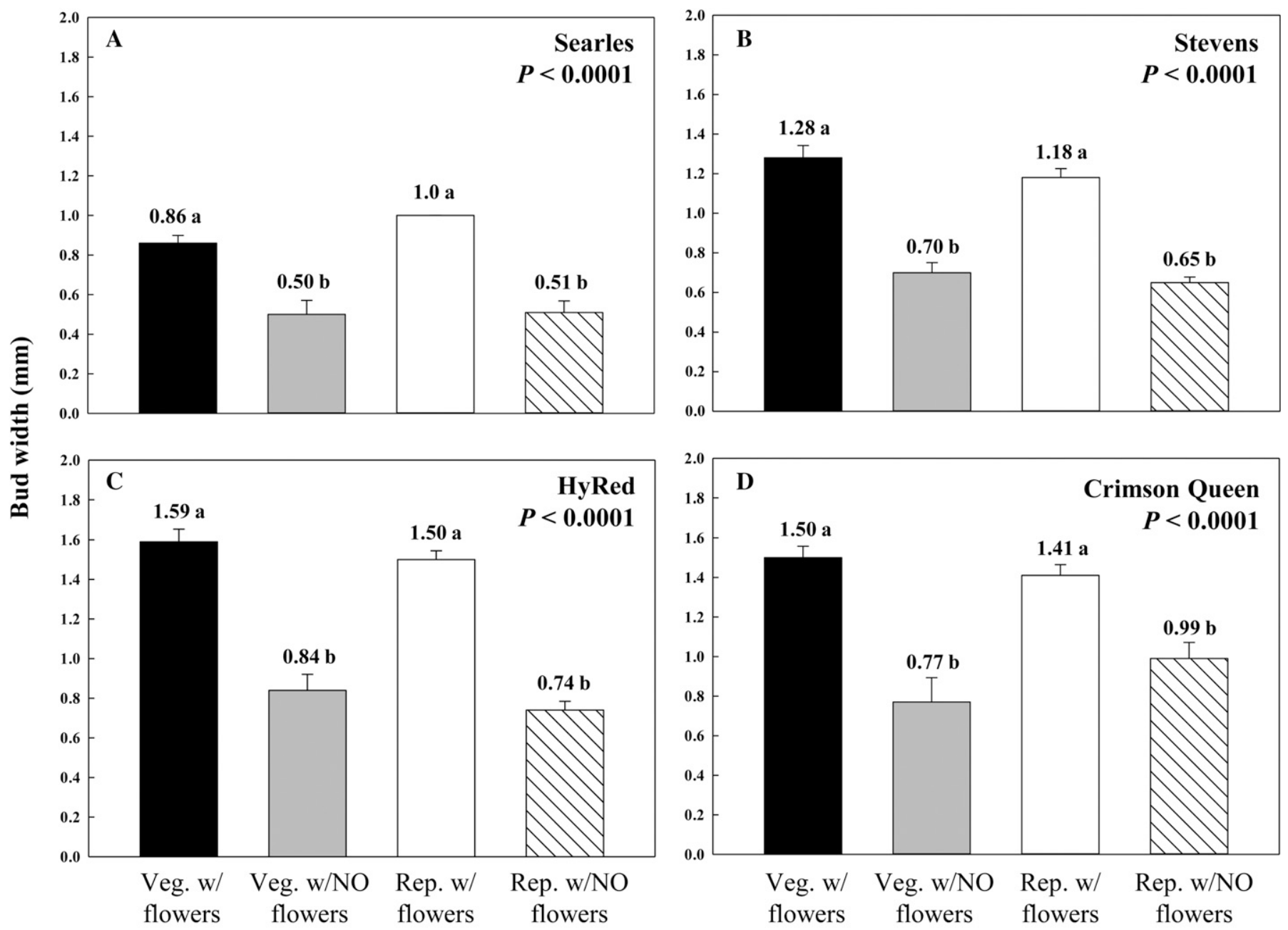

Upright category

Fig. 2. Relationship between bud width and upright category for (A) 'Searles', (B) 'Stevens', (C) 'HyRed', and (D) 'Crimson Queen' cranberries grown in Wisconsin. Values represent mean bud width from 2011 and 2012 (excluding 'Searles', in which no 2012 data were collected). Means with the same letter are not different at $P \leq 0.05$ using a Tukey-Kramer adjustment.

uprights without flower initials in the bud; 3) reproductive uprights with flower initials in the bud; and 4) reproductive uprights without flower initials in the bud. Analysis of descriptive bud data revealed a positive relationship between bud width and the presence of flower initials across all cultivars (Fig. 2). 'Searles' tended to have narrower buds than the remaining cultivars, regardless of the category of upright. The potential for return bloom, estimated by the percentage of reproductive uprights 
with buds containing flower initials, was greatest in 'HyRed' (41.4\%) and 'Crimson Queen' (38.8\%), followed by 'Stevens' $(24.8 \%)$ (Table 4$)$. In contrast, strong biennial bearing tendencies were observed in 'Searles', which is supported by the lower percentage of reproductive uprights with mixed terminal buds.

This study provides quantitative data documenting differences in bud development and potential return bloom across cranberry cultivars. The physiological mechanism by which these cultivars are able to form flowers and fruit in consecutive years remains to be explained. Previous reports suggest allocation patterns of plant resources account for biennial bearing (Baumann and Eaton, 1986; Strik et al., 1991). This explanation proposes internal resources, specifically carbohydrates, are preferentially partitioned to developing fruit at the expense of developing a mixed bud. In support of this, Patten and Wang (1994) found the removal of current- and previous-season leaves reduced the percentage of uprights with apparent mixed buds, as well as other yield components including floral induction and fruit set. These findings provide evidence that both current- and previous-season leaves are involved in the development of fruit and mixed buds.

Although resource limitation may be a contributor to biennial bearing, this study suggests that there are differences between cultivars in their ability to partition resources to both fruit and mixed bud development. The resource-allocation explanation may not fully account for the potential of greater return bloom observed in 'HyRed', 'Crimson Queen', and 'Stevens' (Table 4), which were incidentally the greatest yielding in the study (Table 3). It remains to be confirmed through further investigation if characteristics that enhance resource allocation, such as increased photosynthesis and/or efficiency at partitioning resources to fruit and mixed bud development, have a role in promoting return bloom for cranberry. Nevertheless, our study does not discount the potential role of other factors, such as hormones, nutrients, and other secondary metabolites, as being part of a multifactorial suite of physiological processes that contribute to flower initiation (Bernier et al., 1993).

Environmental factors, such as photoperiod and temperature, may also be involved or interact with physiological processes governing flower initiation. June-bearing strawberry (Fragaria $\times$ ananassa) and southern highbush blueberry (Vaccinium corymbosum interspecific hybrid) are two examples of perennial fruit crops in which both photoperiod and temperature provide signals that elicit flower initiation (Hartmann, 1947;

Table 4. Estimated potential for return bloom exhibited across four cranberry cultivars collected in Wisconsin during the 2011 and 2012 growing seasons.

\begin{tabular}{lc}
\hline Cultivar & Potential return bloom $[\text { mean } \pm \text { SE }(\%)]^{z}$ \\
\hline Searles & $5.6 \pm 4.3 \mathrm{~b}^{\mathrm{y}}$ \\
Stevens & $24.8 \pm 5.1 \mathrm{ab}$ \\
HyRed & $41.1 \pm 2.0 \mathrm{a}$ \\
Crimson Queen & $38.8 \pm 5.5 \mathrm{a}$ \\
$P$ value & 0.0008
\end{tabular}

${ }^{\text {zPotential for return bloom was determined as the percentage of current }}$ season's reproductive uprights with mixed buds.

${ }^{\mathrm{y}}$ Values are means and SE determined from samples collected after harvest in 2011 and 2012 (dates include 9 Sept. 2011, 11 and 24 Oct. 2011, 7 Dec. 2011, and 26 Oct. 2012); 'Searles' was not collected in 2012 as a result of renovation decisions made by the grower; means with the same letter within a column are not different at $P \leq 0.05$ using a Tukey-Kramer adjustment.
Spann et al., 2004). Experiments with rabbiteye blueberry (Vaccinium ashei) have also demonstrated that some cultivars partition greater amounts of carbon to stem tissues and initiate more flowers under short-day conditions (Darnell, 1991). The influence of light on bud initiation and development may also be impacted by canopy shading. Perez and Kliewer (1990) showed that localized shading of grapevine (Vitis vinifera) buds promotes termination of bud development. Cranberry may behave similarly, particularly if upright density and/or vigor is too great and leads to shading of developing buds. All of these studies demonstrate that the physiological process of flower initiation can be greatly influenced by light and temperature. In the case of blueberry, a Vaccinium species like cranberry, such differences exist between cultivars and suggest a genetic component may explain why cultivars within a species respond differently to the environment.

In summary, this project demonstrates that bud development, the potential for return bloom, and external bud appearance differ across cranberry cultivars, whereas timing of floral initiation is consistent across the surveyed cultivars. Newer cultivars released from selective breeding programs outperform traditional cultivars in measures including potential return bloom and yield. Bud width is strongly related to the presence/absence of flower initials and newer cultivars tend to have wider buds. Future work should continue evaluating the physiological and environmental mechanisms that may account for cultivar differences affecting yieldcontributing factors of cranberry. Given the potential increased capacity of recently released cultivars to flower and form fruit in consecutive years, additional research on production requirements (fertility, irrigation, etc.) relative to traditional cultivars is also advised.

\section{Literature Cited}

Baumann, T.E. and G.W. Eaton. 1986. Competition among berries on the cranberry upright. J. Amer. Soc. Hort. Sci. 111:869-872.

Bernier, G., A. Havelange, C. Houssa, A. Petitjean, and P. Lejeune. 1993. Physiological signals that induce flowering. Plant Cell 5:11471155.

Darnell, R. 1991. Photoperiod, carbon partitioning, and reproductive development in rabbiteye blueberry. J. Amer. Soc. Hort. Sci. 116: $856-860$.

DeMoranville, C.J., J.R. Davenport, K. Patten, T.R. Roper, B.C. Strik, N. Vorsa, and A.P. Poole. 1996. Fruit mass development in three cranberry cultivars and five production regions. J. Amer. Soc. Hort. Sci. 121:680-685.

Eaton, G.W. 1978. Floral induction and biennial bearing in the cranberry. Fruit Var. J. 32:58-60.

Eck, P. 1990. The american cranberry. Rutgers University Press, New Brunswick, NJ.

Elle, E. 1996. Reproductive trade-offs in genetically distinct clones of Vaccinium macrocarpon, the american cranberry. Oecologia 107: 61-70.

Goff, E.S. 1901. Investigation of flower-buds. Annu. Rpt. Wisc. Agr. Expt. Sta. 18:304-319.

Hartmann, H.T. 1947. Some effects of temperature and photoperiod on flower formation and runner production in strawberry. Plant Physiol. 22:407-420.

Hawker, G.M. and E.J. Stang. 1985. Characterizing vegetative growth and fruit development in cranberry (Vaccinium macrocarpon Ait.) by thermal summation. Acta Hort. 165:311-324.

Lacroix, D.S. 1926. Cranberry flower-bud investigations. J. Agr. Res. 33:355-363.

Lenhardt, P.J. and G.W. Eaton. 1977. Cranberry flower bud initiation in British Columbia. Fruit Var. J. 31:44. 
Patten, K.D. and J. Wang. 1994. Leaf removal and terminal bud size affect the fruiting habits of cranberry. HortScience 29:997-998.

Perez, J. and W.M. Kliewer. 1990. Effect of shading on bud necrosis and bud fruitfulness of Thompson Seedless grapevines. Amer. J. Enol. Viticult. 41:168-175.

Roberts, R.H. and B.E. Struckmeyer. 1943. Blossom induction of the cranberry. Plant Physiol. 18:534-536.

Roper, T.R. 2006. The physiology of cranberry yield. Wisc. Cranberry Crop Mgt. Nwsl. Vol. XIX. 22 Apr. 2013. <http://scholarworks.umass. edu/cranberry_factsheets/16/>.
Roper, T.R., K.D. Patten, C.J. DeMoranville, J.R. Davenport, B.C. Strik, and A.P. Poole. 1993. Fruiting of cranberry uprights reduced fruiting the following year. HortScience 28:228.

Spann, T.M., J.G. Williamson, and R.L. Darnell. 2004. Photoperiod and temperature effects on growth and carbohydrate storage in southern highbush blueberry interspecific hybrid. J. Amer. Soc. Hort. Sci. 129:294-298.

Strik, B.C., T.R. Roper, C.J. DeMoranville, J.R. Davenport, and A.P. Poole. 1991. Cultivar and growing region influence return bloom in cranberry uprights. HortScience 26:1366-1367. 